\title{
Vínculos de negócios entre grandes empresas compradoras e pequenos fornecedores locais: implicações para políticas públicas e desenvolvimento*
}

\author{
Milber Fernandes Morais Bourguignon** \\ Delane Botelho***
}

SumÁrio: 1. Introdução; 2. Referencial teórico; 3. Método; 4. Resultados; 5. Considerações finais.

Summary: 1. Introduction; 2. Theoretical benchmark; 3. Method; 4. Results; 5. Final remarks.

Palavras-chave: vínculos de negócios; investimento estrangeiro direto; empresas multinacionais; pequenas e médias empresas; políticas públicas.

KEY WORDs: business linkages; foreign direct investment; multinational enterprises; small and medium enterprises; public policies.

Este artigo verifica as condições nas quais os programas e as políticas públicas promotoras de vínculos de negócios (VNs), entre grandes empresas compradoras e pequenos fornecedores locais agem, pressupondo que o Estado tem um importante papel nesse estímulo e que tais vínculos geram desenvolvimento regional e reduzem o desequilíbrio social. A pesquisa empírica, de natureza qualitativa, busca analisar ações e programas de promoção de VNs desenvolvidos no Brasil, bem como as instituições envolvidas, verificar os benefícios dessas ações e identificar oportunidades

\footnotetext{
* Artigo recebido em mar. e aceito em jul. 2009.

** Mestre em administração pública pela Escola Brasileira de Administração Pública e de Empresas da Fundação Getulio Vargas (Ebape/FGV). Administrador da área de comércio exterior do Banco Nacional de Desenvolvimento Econômico e Social (BNDES). Endereço: Av. República do Chile, 100 — Centro - CEP 20031-917, Rio de Janeiro, RJ, Brasil. E-mail: milber@bndes.gov.br.

*** Doutor em administração de empresas pela Escola de Administração de Empresas de São Paulo da Fundação Getulio Vargas (Eaesp/FGV). Professor-adjunto da Ebape/FGV. Endereço: Praia de Botafogo, 190, sala 529 - Botafogo - CEP 22250-900, Rio de Janeiro, RJ, Brasil. Email: delane.botelho@fgv.br.
} 
de intervenção do Estado. Os resultados indicam que políticas públicas podem ser criadas como complemento às políticas de desenvolvimento, voltadas à educação, qualificação de profissionais e incentivadoras de transferência de tecnologia e, de maneira mais ampla, como promotoras de um ambiente propício à atração de investimentos estrangeiros diretos e ao ambiente de negócios. Sugestões de pesquisas futuras são apresentadas como sistemas de governança que abrangem a relação entre as empresas e sua conexão com o setor público.

Business linkages between large buyers and small local suppliers: implications for public policy and development

This article analyzes the conditions under which public policies promoting business linkages (BL) between large and small/medium enterprises act, assuming that the state has a fundamental role stimulating them, and those linkages generate regional development and reduce social inequalities. The empirical research, qualitative in nature, was designed to analyze actions and programs promoting BL developed in Brazil, as well as the institutions involved in it. It also verifies the benefits of those actions and identifies opportunities for public sector intervention. The results show that public policies can be created so as to complement those related to promoting development directed toward education, competence building and technology transfer, and, more generally, to those promoting favorable environment for business and foreign direct investment attraction. The paper also suggests future research, including governance systems involving the relationship between companies and their connection with the public sector.

\section{Introdução}

O desenvolvimento socioeconômico depende de inúmeros fatores, como investimentos dos setores privado e público em educação, saúde, segurança, infraestrutura e inovação tecnológica. As empresas privadas possuem um importante papel neste desenvolvimento, sejam elas grandes multinacionais ou pequenas empresas locais. Entretanto, a simples presença de empresas em determinada região não é suficiente para que ocorra desenvolvimento. Por exemplo: uma grande empresa pode se instalar em uma região menos desenvolvida devido a incentivos fiscais ou custos mais baixos de mão de obra e recursos, e importar mão de obra qualificada, comprar de fornecedores não locais e pouco contribuir para o desenvolvimento regional.

Promover e estreitar o relacionamento entre grandes empresas, multinacionais ou não, e fornecedores locais, geralmente pequenos, em regiões menos desenvolvidas, pode ser um importante estímulo ao desenvolvimento regional. Mas para que isso ocorra sob a ótica de eficiência de mercado é ne- 
cessário que as empresas locais estejam capacitadas a fornecer para as grandes compradoras. Assim, programas que visam o desenvolvimento de fornecedores, entendidos como qualquer atividade iniciada por uma organização compradora para melhorar o desempenho de seu fornecedor (Krause, 1998), vêm ganhando relevância. Em economias em desenvolvimento ou emergentes, o papel do Estado torna-se importante para a promoção de vínculos de negócios (VN), ou business linkages, que acontecem quando grandes empresas (geralmente multinacionais, aqui chamadas de MNCs - multinational corporations) estabelecem relação de compra com empresas fornecedoras locais (geralmente pequenas, aqui chamadas de MPME - micro, pequenas e médias empresas), no país em que a MNC, ou sua filial, está instalada (Giroud, 2006).

VNs são definidos como relações não baseadas em propriedade entre MNCs e empresas nacionais que tenham potencial para gerar spillovers (externalidades que surgem com a presença das empresas grandes, geralmente estrangeiras, proporcionando melhoria na qualidade, produtividade ou eficiência das empresas nacionais, por meio de, por exemplo, transferência de tecnologia e expertise gerencial). A motivação deste artigo reside na crescente atenção dada na literatura (Ivarsson e Alvstam, 2004) sobre a interação entre o nível de desenvolvimento econômico e a capacidade das firmas e países em absorver, gerar e difundir competências, principalmente tecnológica e gerencial.

Nos relacionamentos entre MNCs e MPMEs, estas se beneficiam com aceleração da transferência de tecnologia, aumento de volume de negócios e maior estabilidade comercial, enquanto as MNCs ganham com a redução de custos de produção e distribuição, diminuição de ativos fixos, flexibilidade e maior previsibilidade das entregas (Jenkins et al., 2007). Empresas compradoras estão preocupadas com que seus fornecedores cumpram determinadas exigências técnicas e de qualidade, e o desenvolvimento de fornecedores pode representar ações para o atendimento de interesses exclusivos. Mas ao iniciar um programa como esse, a empresa também agrega valor a seu fornecedor e aos seus funcionários, por meio de aumento da qualificação técnica e gerencial e, algumas vezes, com investimentos financeiros ou em bens de capital. Isso possibilita que a empresa fornecedora aumente seu volume de negócios e busque novos mercados para sua produção. Como esses programas promovem desenvolvimento regional, o Estado, como agente de regulação econômica e promotor de desenvolvimento social, é um dos interessados na expansão desses tipos de programas, especialmente nos casos em que empresas tiverem como principais fornecedores empresas de outras regiões mais desenvolvidas ou de outros países. 
Assim, em regiões mais carentes, onde os VNs não ocorrem de maneira espontânea, o Estado pode estimular programas dessa natureza por meio de políticas públicas. A relevância desse estímulo, na perspectiva do Estado, é o desenvolvimento regional sustentável. Estimular o relacionamento entre grandes compradores e fornecedores locais significa dinamizar a economia local, por meio do fortalecimento das MPMEs e por criar um ambiente propício para a atração de novas grandes companhias. $\mathrm{O}$ foco de médio e longo prazos pode permitir às empresas fornecedoras aprender com as grandes compradoras, construindo-se um ciclo virtuoso, cujos benefícios ocorrem para ambas, sem significar, portanto, exploração momentânea de recursos mais baratos, com o foco em ganhos de curto prazo.

Este artigo busca compreender as condições dos programas de políticas públicas que podem promover VN entre MNCs e MPMEs, com vistas ao desenvolvimento. Portanto, alguns objetivos intermediários precisam ser alcançados: analisar ações e programas de promoção de VN desenvolvidos no Brasil e suas respectivas instituições; verificar os benefícios dessas ações e programas aos participantes; identificar oportunidades de ação do Estado para a promoção de VN.

O artigo está estruturado da seguinte forma: a introdução, que apresenta o tema, justificativa e objetivos. O próximo tópico apresenta o referencial teórico, abordando, principalmente, o relacionamento entre as empresas, o ambiente de investimentos no Brasil e o esforço brasileiro de desenvolvimento de empresas via programas e políticas públicas. A seguir, é apresentado o método da pesquisa empírica e a discussão dos resultados. $\mathrm{O}$ artigo é finalizado com as principais conclusões, implicações para políticas públicas e sugestões para futuras pesquisas.

\section{Referencial teórico}

\section{Programa de desenvolvimento de fornecedores}

O relacionamento entre empresas é discutido em diversas divisões acadêmicas das ciências sociais, como em logística, produção e marketing, especialmente o marketing industrial que, como grande área do estudo, preocupa-se em entender como são os relacionamentos entre as empresas, no que se refere à compra e à venda de produtos, e quais são as melhores estratégias que façam com que os laços de negócios estabelecidos gerem maior valor para ambos os lados: compradores e fornecedores (Moreira, 2002). 
Webster Jr. (1991) mostra as peculiaridades do processo de compras industriais e as separam em um corpo analítico diferenciado das compras dos consumidores finais. A primeira é a interdependência funcional, pois as empresas em transações industriais dependem mais dos setores técnicos, como pesquisa e desenvolvimento, engenharia e desenvolvimento de produtos. Assim, a relação do setor de marketing com as outras áreas tende a ser mais forte do que nas empresas orientadas ao consumidor final. Nas relações industriais, caracterizadas por uma relativa dependência mútua entre as empresas, o processo de compra tende a possuir uma perspectiva muito menos transacional, adquirindo um perfil mais próximo do relacional, pois o marketing de relacionamento tem o objetivo de manter clientes, desenvolver uma relação que tenha como principal objetivo a continuidade de compras a médio e longo prazos. Mas as relações entre as empresas não são completamente explicadas por relação ou transação, pois as duas perspectivas se complementam e, de acordo com o momento, uma ou outra será mais adequada para a solução de um problema específico (Coviello e Brodie, 1998).

Considerando que a cadeia de valor refere-se ao conjunto de atividades desempenhadas por uma organização desde as relações com os fornecedores e ciclos de produção, e de venda até a fase da distribuição final, o relacionamento entre comprador-fornecedor, foco deste artigo, é um ponto-chave nessa cadeia. Gefferi e outros (2005) define cadeia de valor, produção ou suprimentos como o processo realizado por uma empresa ou por um conjunto delas, pelo qual a tecnologia é combinada com entradas de trabalho e materiais, e com a organização desses insumos orientados a um mercado e distribuídos. Esperase que, de acordo com a teoria da cadeia de valor e na perspectiva das firmas compradoras, melhorias no desempenho da cadeia somente sejam possíveis quando estabelecidos compromissos de longo prazo com seus fornecedoreschave (Krause, 2007).

Grandes empresas compradoras, aqui chamadas de MNCs, geralmente possuem consumidores com altos níveis de exigência de qualidade, baixa tolerância a defeitos e atuam em ambientes supercompetitivos de natureza global (Shen, 2008). Tais empresas têm objetivado tanto a redução do número de fornecedores quanto o aumento de sua eficiência. Quando há necessidade de flexibilidade, pode haver terceirização de algumas etapas da produção e nem sempre as empresas pequenas locais estão aptas a responder às suas expectativas. Assim, muitas vezes é mais interessante para as grandes empresas investir em seus próprios fornecedores, por meio de treinamento gerencial e técnico, resultando em programas para melhoria da qualidade de fornecedores, os chamados programas de desenvolvimento de fornecedores (PDFs). 
Para Langfield-Smith e Greenwood (1998), esse é o momento em que muitas empresas identificam os fatores que lhes tornam passíveis de mudar de uma relação caracterizada por grandes conflitos na relação comprador-fornecedor, marcada, principalmente, por poder e barganha para uma relação de parceria, baseada em confiança e cooperação.

Os PDFs referem-se aos esforços organizacionais sistemáticos para criar e manter uma rede de fornecedores capacitados (Silva, 2004). A assistência ou colaboração técnica, uma das muitas maneiras de se desenvolver fornecedores, pode ocorrer pelos seguintes motivos: enquadramentos nas especificações exigidas pelo comprador; redução de preços; garantia de fornecimento ininterrupto. A transferência de capacidades organizacionais da empresa compradora para sua fornecedora requer não apenas comprometimento financeiro e de recursos, mas também uma distinta estrutura organizacional e de governança que facilite a acumulação de conhecimento em longo prazo (Sako, 2004).

Há vários estudos sobre relacionamento entre empresas compradoras e fornecedoras em países em desenvolvimento. Por exemplo: Kumar e Bergstrom (2008) investigaram um modelo de relacionamento entre empresas em longo prazo em tais países, e concluíram que quanto mais desenvolvido era o mercado comprador, melhor o fornecedor local era tratado pela MNC e mais forte era a relação entre tais empresas. Jeppesen e Hansen (2004) descrevem os padrões de transferência de tecnologias de gestão de MNCs para seus fornecedores em países menos desenvolvidos, que se dividem em três modelos principais: determinação de padrões; controle e monitoramento; colaboração técnica. Tais padrões formam um continuum que vai de pouca (determinação de padrões) a muita (colaboração técnica) interação entre as empresas. Na determinação de padrões, a empresa cliente exige produtos com certificados de órgãos reconhecidos internacionalmente. A procura pela adequação faz com que a fornecedora se desenvolva tecnologicamente. O controle e monitoramento acontecem com padrões impostos pelos clientes, acompanhados de vários mecanismos de controle, como no caso do "Certificado Michelin" fornecido aos distribuidores que atendem a padrões de qualidade exigidos por esta empresa (Pneuvita, 2008). A colaboração técnica ocorre quando empresas grandes oferecem assistência técnica para seus fornecedores a fim de que eles atinjam os padrões desejados, geralmente com o envio de equipe técnica especializada às unidades do fornecedor, de maneira a estreitar o relacionamento entre as duas empresas. Ivarsson e Alvstam (2004) também investigaram a transferência de tecnologia em países com o mesmo estágio de desenvolvimento, chegando aos seguintes resultados: transferência de tecnologia das economias 
industrializadas para aquelas em desenvolvimento são, basicamente, baseadas em vínculos entre empresas, principalmente no setor de manufatura (e não em pesquisa e desenvolvimento); os fornecedores assistidos pelas MNCs não foram igualmente beneficiados, confirmando que tais benefícios dependem das capacidades tecnológicas iniciais dos fornecedores, de sua habilidade de absorção de tecnologia e de aprendizado; relações de longo prazo baseadas em confiança são importantes para a colaboração e aprendizado entre empresas, entretanto mesmo em relacionamento de curto prazo geraram benefícios para os fornecedores, no sentido de melhorarem sua capacidade tecnológica e prospectarem novos mercados.

Embora muitas vezes os PDFs sejam criados e desenvolvidos pelo setor público nos países em desenvolvimento, eles vêm sendo providos pelo setor privado nos países mais desenvolvidos (Shen, 2008). O setor público também é responsável, em grande parte, pela atração de investimentos para um país, que pode ser na forma de atração de MNCs que se instalam com possibilidade de geração de spillovers, o que pode ser mais interessante em regiões ainda menos desenvolvidas, como o Norte e o Nordeste brasileiro.

\section{Investimentos e desenvolvimento}

De acordo com United Nations Conference on Trade and Development (2006), os fluxos internacionais de capitais podem ter basicamente as seguintes razões: busca de mercados, a mais comum de todas (do inglês, market-seeking); busca de eficiência produtiva (efficiency-seeking); busca de recursos (resourceseeking); fusões e aquisições (created asset-seeking). Na busca de mercados, as empresas objetivam ofertar seus produtos para a economia na qual se instala e para seus vizinhos, como no caso da fábrica da Mercedez-Benz no Brasil que, inicialmente, produzia carros para o mercado nacional e América do Sul. A busca de eficiência produtiva ocorre quando a empresa tem o objetivo de aperfeiçoar a distribuição das unidades, de maneira a obter as melhores dotações de cada país receptor, pelo aumento de eficiência por dotação em local de destino e ganho de escala. A busca de recursos se caracteriza pela aquisição de recursos específicos a baixo custo, baseando-se na racionalidade neoclássica de dotação de fatores, por exemplo, quando empresas petrolíferas exploram petróleo e/ou gás natural em países com grandes reservas, investindo na construção de plantas industriais. Fusão refere-se à combinação de duas ou mais empresas em uma empresa maior; e aquisição refere-se à compra de uma empresa por outra. 
O investimento realizado pelas MNCs envolve transferência de um pacote de ativos ou produtos intermediários, experiência administrativa, tecnologia e acesso a mercados estrangeiros, com os recursos investidos ainda em propriedade da entidade que realiza os investimentos (Gonçalves, 2005). O papel do governo na garantia após a atração de capitais internacionais é um importante mecanismo, pois os recentes processos de nacionalização de empresas multinacionais ocorridos na Bolívia em 2006 (setores de gás e petróleo) e na Venezuela em 2007 e 2008 (cimento e telecomunicações) diminuem a confiança de empresas para o investimento de capitais em países com maiores instabilidades comerciais e/ou com risco político percebido como elevado. Governos, em geral, perderam poder de barganha para as MNCs, principalmente nos países em desenvolvimento. Os Estados ainda controlam o acesso ao território e à mão de obra, mas empresas controlam capital e tecnologia, o que elevou consideravelmente seu poder de barganha.

As MNCs são importantes fontes de renda e desenvolvimento, mas, proporcionalmente, têm oferecido poucas oportunidades de empregos diretos. Em 2008 atuavam no Brasil 420 MNCs das 500 maiores do mundo, mas estima-se que o total de afiliadas de multinacionais no país seja responsável por apenas $2 \%$ dos empregos (Observatório Social, 2005). Por outro lado, as MPMEs eram responsáveis por 17,2 milhões de empregos formais em 2006, contra 8,8 milhões das grandes empresas (aquelas com mais de 500 empregados na indústria ou 100 empregados no setor de serviços) (Serviço Brasileiro de Apoio às Micro e Pequenas Empresas, 2008).

A maioria dos países possui agências de promoção de investimento (API) nacionais ou regionais, com o objetivo não apenas de atrair mais investidores (estrangeiros), mas também concentrar-se na criação de empregos, exportações e transferências tecnológicas associadas aos fluxos destes investimentos. Exemplos de APIs brasileiras incluem a Apex (Agência Brasileira de Promoção de Exportações e Investimentos), Indi (Instituto de Desenvolvimento Integrado de Minas Gerais) e Investe São Paulo (Agência Paulista de Promoção de Investimentos e Competitividade). $\mathrm{O}$ interesse das MNCs em se relacionar com tais agências segue as lógicas de negócio e economia, já que podem significar divisão de custos para o desenvolvimento das MPMEs, além do fato de que as APIs têm interesse no desenvolvimento de uma região, não de uma empresa específica (United Nations Conference on Trade and Development, 2006).

\section{Vínculos de negócios (VN) e sua promoção}

Os VNs podem ser "horizontais", entre competidores; "colaborativos", com parceiros nacionais para fins estratégicos, tecnológicos ou gerenciais; ou "ver- 
ticais", com fornecedores, agentes ou clientes nacionais, sejam eles licenciados ou franqueados. As afiliadas estrangeiras podem contribuir para aumentar as capacidades dos fornecedores ou clientes nacionais por meio da melhoria dos padrões de qualidade e eficiência da produção, bem como pela prestação de assistência e fornecimento de recursos relativos à aquisição, projeto, controle de qualidade, treinamento ou informação de mercado. Esses vínculos verticais podem ocorrer "a montante" (com fornecedores e subcontratados), que é o foco deste artigo, "a jusante" (com os clientes e agentes) ou de natureza contratual (com franqueados e licenciados nacionais) (Kennel, 2007).

Diferentes tipos de MNCs podem, por meio de distintas combinações de vínculos, exercer diferentes impactos sobre as empresas nacionais e o desenvolvimento como um todo. Exemplos de contextos de VN incluem (MeyerStamer, 2005):

- os arranjos produtivos locais (APLs), grupos de empresas que surgiram com a concentração geográfica delas, podendo gerar alta competitividade e potencial exportador para o grupo. Incluem os consórcios de exportação, cooperativas para organização de compras e vendas etc.;

- o desenvolvimento da cadeia de valor, consistindo em agregados espaciais maiores que os APLs, nos quais produtores fazem parte de uma cadeia de valor, com várias etapas de transformação até a finalização do produto.

As relações de poder podem ser simétricas (tamanhos similares entre os fornecedores e os compradores, por exemplo), ou assimétricas, quando MNCs se relacionam com MPMEs, geralmente com escopo de atuação local, como é o foco deste artigo. No caso das assimetrias, estruturas de governança passam a integrar as relações, como instrumento de fiscalização das diferenças de poder (Meyer-Stamer, 2005).

A razão principal de uma MNC ter um fornecedor local é a de que a importação torna-se desnecessária, diminuindo riscos de longos lead times (tempo entre uma solicitação e a entrega), evitando, portanto, obstáculos em portos e alfândegas, especialmente críticos no caso brasileiro, além de menores custos em transportes e flexibilidade nas compras, já que o fornecedor local pode atender mais facilmente às variações inesperadas de demanda. Outros aspectos são importantes, como manter governos locais e outros stakeholders satisfeitos com o desenvolvimento da economia local e fortalecer a imagem de uma companhia cidadã, socialmente responsável, indo além dos patrocínios tipicamente desenvolvidos como responsabilidade social (United Nations Conference on Trade and Development, 2006). 
Na promoção de VN, governos geralmente têm dois desafios principais: promover a competitividade das firmas nacionais e promover a troca de informações e o crescimento de consciência das exigências de MNCs para com as empresas domésticas, e destas para a existência daquelas. Políticas públicas de caráter mandatório (como obrigar a MNC a comprar localmente) podem não surtir efeito por contrariarem, muitas vezes, a lógica de eficiência do mercado, sendo preferíveis aquelas políticas que se desenvolvem por meio de estímulos positivos (Giroud e Botelho, 2008). Atrair e fazer com que as MNCs queiram desenvolver fornecedores domésticos é tão importante quanto fazer com que estas estejam abertas para o relacionamento com as MNCs. E, para que isso aconteça, é necessário que elas possuam consciência de que existem essas possibilidades, além de se prepararem para o evento.

Assim, políticas de desenvolvimento de vínculos baseadas em regras com deveres de atuação podem ser prejudiciais para o governo que as desenvolve. Primeiramente, porque as empresas locais podem não estar preparadas, depois, porque tais regras podem afastar os investimentos e, uma vez que a regra tenha sido cumprida, pode não haver o comprometimento para a efetivação dos resultados. Então, governos usam, de modo geral, medidas para atrair investidores e influenciar suas atividades com a criação de um ambiente de negócios e investimentos no qual as relações de ganho entre empresas podem ser maximizadas, por meio da criação e desenvolvimento de VN.

\section{Políticas públicas e esforço brasileiro de desenvolvimento de empresas}

O Estado brasileiro sofreu modificação em seu papel desde o período ditatorial, passando da figura de um grande planejador para a de agente regulador das ações de empreendimentos privados. O instrumento de planejamento governamental integrado foi substituído pelas políticas públicas pontuais, com foco de ação, mas integradas com o conceito de Estado. Em face dessas evoluções, instituições se transformaram e muitas outras surgiram. Assim, o Estado deixa de ser aquele que, de fato, gera o crescimento do país e passa a ser o que coordena, incentiva e promove o desenvolvimento por meio das políticas públicas setoriais. Às empresas cabe o setor produtivo, sendo as responsáveis por abertura de empregos, geração de valor agregado e criação de riqueza. É a partir da boa relação entre Estado e setor privado que se tem o crescimento do país com o objetivo de equilíbrio social. 
O conceito de política pública está diretamente relacionado à ação do Estado, ao modo como ele age e às decisões relativas ao bom funcionamento da administração pública. Quando seu papel era o de grande planejador, a dinâmica ocorria por meio do planejamento governamental, mas, com a evolução de seu conceito, especialmente a reformulação de seu papel, surge uma nova maneira de atuação: as políticas públicas. Desenvolvida nos anos 1980, ela substitui a ideia de ação do Estado de forma planejada pela ideia de ações de caráter pontual, no atendimento de demandas, permitindo uma visão mais ágil e flexível das realizações de governo que visam ao bem-estar de alguma parcela da sociedade, ou dela como um todo (Saravia, 2006). De maneira geral, pode-se entender que a política pública é uma intervenção, com o fim público, a fim de se manter uma situação desejada ou modificá-la para alguma situação desejada, orientada por finalidades, para uma determinada situação final, com uma perspectiva de prazo de atuação e de consequências da ação.

Desde o início dos anos 1980, em todo o mundo se constata uma força global de reforma do setor público, com praticamente todos os governos tendo empreendido esforços para modernizar e agilizar a administração pública. Todas as correntes de pensamento giram em torno da ineficiência do Estado, associada a seus custos, os impostos (Kettl, 2003). Ao mesmo tempo, tem-se a constatação de que o Estado neoliberal (mínimo), defensor de o mercado coordenar totalmente a economia, fracassou por não ter legitimidade política (Bresser-Pereira, 2003).

Logo após a crise do endividamento internacional nos anos 1980, o tema que prendeu a atenção de formuladores de políticas públicas em todo o mundo foi o ajuste estrutural, ou seja, o ajuste fiscal e as reformas do Estado orientadas para mercado. O significado da reforma é o de o Estado limitar suas funções como a de produtor de bens e serviços e, em menor extensão, como regulador, mas também ampliar suas funções no financiamento de atividades que envolvam benefícios sociais, por exemplo, externalidades positivas ou direitos humanos básicos, bem como a promoção da competitividade internacional das indústrias locais (Bresser-Pereira, 2003).

A reforma da administração pública nunca havia avançado tão rapidamente e de maneira tão profundamente como nos anos 1980 (Kettl, 2003). De modo geral, as ações governamentais para a atração de investimentos começou no final dos anos 1980 e início dos anos 1990, quando o país passou por transformações que o colocavam nos moldes das economias mais desenvolvidas da época. Depois desse início, os governos desenvolveram mais políticas de atração de investimento estrangeiro direto (IED). 
A estrutura brasileira para promoção de investimentos é complexa, pois é desenvolvida por um sistema federal de instituições, agências de promoção de investimentos, bancos públicos (estaduais e federais) e privados de desenvolvimento, além das organizações não governamentais (Giroud e Botelho, 2008), como mostra o quadro.

\section{Principais categorias de funções de APIs (ou instituições de desenvolvimento com funções de promoção de investimentos) no Brasil e alguns exemplos}

\begin{tabular}{|c|c|}
\hline $\begin{array}{l}\text { Sistema nacional de instituições } \\
\text { v Agência de Promoção de Investimentos } \\
\text { (Apex) } \\
\text { v Sistema para a Promoção de Investimentos } \\
\text { e a Transferência de Tecnologia para as } \\
\text { Empresas (Sipri) }\end{array}$ & $\begin{array}{l}\text { APIs originadas dos bancos estaduais de } \\
\text { desenvolvimento } \\
\text { v Agência de Fomento de Goiás } \\
\text { (GoiásFomento) } \\
\text { v Agência de Fomento do Rio Grande do Norte } \\
\text { (AGN) }\end{array}$ \\
\hline $\begin{array}{l}\text { APIs compostas pelo governo e organizações } \\
\text { privadas } \\
\text { v Agência de Desenvolvimento Econômico } \\
\text { Pernambuco (AD Diper) } \\
\text { I Instituto de Desenvolvimento Industrial (Indi) } \\
\text { de Minas Gerais }\end{array}$ & $\begin{array}{l}\text { Organização privada sem fins lucrativos } \\
\text { v Agência de Desenvolvimento do Rio Grande } \\
\text { do Sul (Polo-RS) }\end{array}$ \\
\hline
\end{tabular}

Fonte: Giroud e Botelho, 2008.

O Ministério do Desenvolvimento Indústria e Comércio Exterior é o principal responsável por coordenar as políticas de assistência às empresas, adquirindo mais importância em 2007, com o fortalecimento do Fórum Permanente de Pequenas e Micro Empresas (criado em 2000), com o Estatuto Nacional da Micro e Pequena Empresa (Botelho e Pfister, 2008). A Constituição Brasileira estabelece tratamento diferenciado para micro e pequenas empresas, por estarem em posição menos favorável, por meio desse instrumento, que é o Estatuto, regulado por força de lei, com medidas que se aplicam a questões administrativas, fiscais, do sistema de seguridade social e de direitos de trabalho. Ainda existe no país a Lei Geral da Micro e Pequena Empresa, que visa unificar os impostos federais, estaduais e municipais para MPMEs, reduzindo o montante tributário na maioria dos casos, além de facilitar a formalização de empresas, acesso a crédito e à tecnologia. Em 2007 foi a primeira política determinando o pagamento unificado de impostos dos três níveis da administração pública (Giroud e Botelho, 2008). 
Duas instituições possuem grande importância para o país na promoção de um ambiente propício para a melhoria do espaço de negócios e, indiretamente, para a promoção de VN: o Banco Nacional de Desenvolvimento Econômico e Social (BNDES) e o Serviço Brasileiro de Apoio às Micro e Pequenas Empresas (Sebrae). Esta última foi criada em 1972 e é uma entidade privada sem fins lucrativos que tem como missão promover a competitividade e o desenvolvimento sustentável dos empreendimentos de empresas de micro e pequeno portes. Como resultado da união dos setores públicos e privados, sua principal fonte de renda é a contribuição obrigatória que as empresas pagam associadas ao Instituto Nacional do Seguro Social (INSS), sendo completamente independente do poder público.

O governo brasileiro desenvolveu em 2004 uma nova política de competitividade, a política industrial, tecnológica e de comércio exterior (PITCE), que tinha como objetivo o aumento da eficiência econômica e do desenvolvimento e difusão de tecnologias com maior potencial de indução do nível de atividade e de competição no comércio internacional. Quando criada, estava focada no aumento da eficiência da estrutura produtiva, aumento da capacidade de inovação das empresas brasileiras e expansão das exportações. Os setores contemplados eram os intensivos em capital, compostos de grandes empresas, com orientações que visam tanto às políticas de desenvolvimento horizontais, quanto às verticais, por meio de acesso ao crédito e atração de investimentos (Ministério do Desenvolvimento, Indústria e Comércio Exterior, 2009; Giroud e Botelho, 2008).

No primeiro semestre de 2008 foi desenvolvida a política de desenvolvimento produtivo (PDP), em substituição à PITCE, com a definição de quatro macrometas até o ano de 2010: aumento da taxa de investimento; ampliação da participação das exportações brasileiras no comércio mundial; elevação do gasto privado em pesquisa e desenvolvimento; ampliação de número de MPMEs exportadoras. Tem-se o objetivo de elevar a participação do investimento fixo no PIB para $21 \%$ em 2010 (o que exigirá um crescimento médio anual de $11,3 \%$ da formação bruta de capital fixo) e elevar de 0,51\% do PIB para $0,65 \%$ os gastos em pesquisa e desenvolvimento. No que se refere às exportações, espera-se para 2010 atingir US\$ 208,8 bilhões (contra US\$ 160,6 bilhões em 2007), aumentando a participação do país nas exportações mundiais para $1,25 \%$, em valor. Para a quarta macrometa objetiva-se aumentar em $10 \%$ o número de MPMEs exportadoras, com 12.971 MPMEs exportadoras até 2010, diante de 11.792 MPMEs em 2006 (Ministério do Desenvolvimento, Indústria e Comércio Exterior, 2009). 
Assim, o Brasil parece trabalhar no sentido de promover as MPMEs, mas o país carece de políticas públicas focadas especificamente na promoção de VN. Em estudo realizado por Almeida e outros (2007), cujo objetivo foi o de mapear o status das atividades relacionadas a VN no país, não foi encontrada nenhuma política pública de nível federal que se enquadrasse nesse modelo, apesar de que políticas e programas com outros objetivos poderiam, de alguma forma, contribuir para a geração de VN.

As políticas de desenvolvimento de empresas no Brasil focam genericamente setores e empresas: quase $60 \%$ das políticas estão centradas em financiamento de negócios e desenvolvimento de gestão como um todo e não em áreas empresariais específicas, como logística ou gestão de pessoas, ou setores específicos da indústria. A maioria dessas políticas é da esfera federal, totalizando, em 2006, 67 políticas públicas. Sessenta por cento são do governo federal e 40\% de agências de promoção, em que se enquadram o BNDES, Caixa Econômica Federal (CEF), Banco do Nordeste e Banco do Brasil. Na classificação de perfil de atuação, 38\% são workshops setoriais, $32 \%$ fundos para financiamento de desenvolvimento corporativo, 21\% para programas de desenvolvimento, $7 \%$ para incentivos fiscais e de investimentos e $3 \%$ das agências de desenvolvimento (Almeida et al., 2007).

Ainda que o Brasil possua políticas voltadas, mesmo que indiretamente, para as etapas de formação de vínculos, é importante desenvolver políticas públicas que façam com que esses arranjos se articulem de modo a gerar VNs duradouros. Em termos de fontes potenciais de geração de vínculos, os programas de desenvolvimento e agências de desenvolvimento são mais efetivos do que aqueles caracterizados pelo simples incentivo financeiro (Almeida et al., 2007). Complementando, Botelho e Pfiser (2008) afirmam que o estabelecimento de vínculos sustentáveis de negócios não acontece pela simples demanda de grandes empresas. Requer a visão de compromisso das empresas que se relacionam e a participação de todos os stakeholders: governos, agências de promoção de investimentos, câmaras de comércios, bancos de fomento, associações de empresas, organizações não governamentais, mídia, universidades e institutos de pesquisa.

O cenário brasileiro, portanto, mostra-se favorável para o desenvolvimento de VN, pois os quesitos principais para que eles ocorram vêm sendo cumpridos. Primeiramente, o Brasil possui um grande número de micro e pequenas empresas (em 2002 elas representavam 99,2\% do número total de empresas formais, por $57,2 \%$ dos empregos totais e por $26 \%$ da massa salarial), sob legislação que as trata de forma diferenciada. Existem, por parte do poder público, diversos programas de apoio a essas empresas, permitindo que 
elas busquem, de maneira autônoma, melhorias para atingir um bom grau de desenvolvimento. Por outro lado, o ambiente brasileiro também se mostra atraente para empresas internacionais: tem havido estabilidade econômica, em comparação com as duas últimas décadas, e os fluxos de IEDs ocorrem em conformidade com os fluxos internacionais (em 2007 o Brasil recebeu US\$ 34,6 bilhões em IED) (United Nations Conference on Trade and Development, 2008).

\section{Método}

Com o objetivo de analisar programas de promoção e fortalecimento de VN foram utilizados como referência o Projeto Vínculos e os principais PDFs brasileiros, descritos adiante. O Projeto Vínculos foi escolhido por ter o objetivo de criar, promover e desenvolver VN nas regiões menos desenvolvidas do Brasil, especificamente Norte e Nordeste, e de fortalecer MPMEs em busca do desenvolvimento regional, por meio do aumento da capacidade produtiva local e da eficiência do setor empresarial doméstico (Projeto Vínculos, 2009). Os PDFs foram considerados por terem como principal objetivo acelerar o crescimento regional pela participação das empresas locais nos grandes investimentos de MNCs, também chamadas de empresas âncoras nesses programas, especialmente de setores da indústria de base, como siderurgia, mineração, papel e celulose (DVF Consultoria, 2008). Todos os projetos aqui analisados têm o objetivo básico de fortalecer as relações entre grandes empresas (âncoras) com MPMEs locais, prestadoras de serviços e fornecedoras de bens.

O Projeto Vínculos surgiu em 2004, em virtude da XI Conferência das Nações Unidas sobre Comércio e Desenvolvimento, realizada no Brasil. É resultado de cooperação entre a GTZ (Agência de Cooperação Alemã), a Unctad, o Instituto Ethos, a Fundação Dom Cabral e o Sebrae. É formado por um comitê gestor com o objetivo de articular empresas, entidades de classe e organizações que possam gerar VNs sustentáveis em determinada região. Esse comitê toma as decisões estratégicas e direciona as ações do Projeto Vínculos, determinando, por exemplo, estados de atuação e número de empresas participantes.

Os PDFs possuem estrutura diferente, baseada em uma metodologia específica, e sua gestão fica a cargo das instituições que tomam a iniciativa de aplicação da metodologia. No PDF-Maranhão foi o governo do estado quem teve a iniciativa para aplicação da metodologia, enquanto no PDF-Pará a iniciativa foi de uma MNC. Fazer uma análise dos PDFs e do Projeto Vínculos 
permite avaliar a atuação do poder público no que se refere à participação em programas geradores de $\mathrm{VN}$.

O desenho da pesquisa foi um estudo de caso múltiplo, já que o mesmo objeto de estudo, programas geradores de $\mathrm{VN}$, possui mais de um caso passível de estudo (Yin, 2005). Por se tratar de uma pesquisa de caráter exploratório, utilizou-se como método de coleta de dados a entrevista em profundidade, com um total de 14 respondentes, sendo 11 por telefone, dois pessoalmente e um por e-mail. Tais entrevistas foram realizadas nos meses de maio a julho de 2008, com médias de duração de 40 minutos. Foram entrevistados representantes-chave de quatro APIs: a Agência de Fomento do Rio Grande do Norte (AGN) e a Agência de Desenvolvimento do Rio de Janeiro (AD-Rio), para compreensão do funcionamento das agências de fomento e sua relação com o poder público; a API do estado do Rio Grande do Sul, Polo RS, caracterizada pela liderança da iniciativa privada, em conjunto com as entidades de classe e com o governo local; a Apex, para compreensão da perspectiva do governo federal na promoção de VN.

Foram entrevistados seis representantes de organizações desenvolvedoras de vínculos: Federação das Indústrias do Estado da Bahia (Fieb), Projeto Vínculos (Pernambuco, Bahia e Ceará), DVF Consultoria, PDF-Espírito Santo, que está ligado ao Sindicato da Indústria da Construção Civil do Espírito Santo (Sindicon) e da Federação das Indústrias do Espírito Santo (Findes), PDFPará, ligado diretamente à Federação das Indústrias do Estado do Pará (Fiepa) e PDF-Maranhão, ligado diretamente ao governo estadual, por meio da Secretaria de Estado da Indústria e Comércio (Sinc). Também foram entrevistados executivos de duas MNCs e duas fornecedoras pequenas locais.

Todas as entrevistas pessoais e por telefone foram gravadas e transcritas. Os roteiros de entrevista possuíam subcategorias nas quais as respostas se enquadrariam, com perguntas relacionadas aos padrões de relacionamento entre empresas e tipos de produtos comercializados. Entretanto, novas dimensões de análise foram se desenvolvendo com as entrevistas e as respostas foram estruturadas em categorias, cujos resultados e análises são mostrados a seguir.

\section{Resultados}

Foram analisados três subprogramas do Projeto Vínculos: o Programa de Qualificação de Fornecedores (PQF) na Bahia, o Projeto Vínculos Pernambuco e o Projeto Vínculos Ceará. O PQF se desenvolve com recursos das grandes em- 
presas (âncoras) e das empresas fornecedoras, com contribuições mensais, em uma proporção de, aproximadamente, $70 \%$ e $30 \%$, respectivamente. Com o objetivo de dar foco ao desenvolvimento dos fornecedores, cada empresa âncora indicou 10 fornecedores. Assim, o programa se iniciou com o objetivo de fortalecer VNs já existentes. Também se nota que há uma restrição à entrada de novas empresas fornecedoras: somente quando novas âncoras entram no programa, com a entrada de 10 empresas fornecedoras para cada empresa âncora, ou quando alguma empresa fornecedora atinge todo o ciclo de desenvolvimento, abrindo vaga para outra fornecedora.

Quando os organizadores do Projeto Vínculos conheceram a estrutura de funcionamento do PQF na Bahia foram estabelecidas algumas rodadas de negociação e, com o entendimento de que ambos os programas possuíam objetivos em comum, os administradores dos dois programas iniciaram parceria. Assim, o primeiro desenvolvimento de ações do Projeto Vínculos ocorreu na Bahia. A parceira ocorreu com um aporte financeiro para o PQF, que já possuía a metodologia em desenvolvimento, permitindo que um número maior de empresas fornecedoras participasse do programa. A metodologia desenvolvida pelo PQF foi aplicada também no Projeto Vínculos do Ceará e de Pernambuco.

O PDF surgiu a partir da parceria de empresas, poder público e a uma consultoria especializada. O modelo de trabalho começou em 1995, com atuação no Espírito Santo, por solicitação de grandes empresas, como a então Vale do Rio Doce, com o nome de Programa de Potencialização do Crescimento. Nesse momento foram articulados diversos setores relevantes do Espírito Santo, como Sindicato das Empresas das Indústrias de Base da Construção Civil, Industrial e Metal-Mecânica. Um programa semelhante foi desenvolvido no estado de Minas Gerais e aplicado em outros estados. Hoje, como programas estruturados, existem três PDFs nos estados do Espírito Santo, Maranhão e Pará.

O PDF e o Projeto Vínculos possuem objetivos semelhantes: capacitar fornecedores para melhor atendimento às grandes empresas locais, além de fortalecer o ambiente de negócios. Além disso, ambos articulam entidades de classe e serviços de desenvolvimento de negócios, como Sebrae e Senai (Serviço Nacional de Aprendizagem Industrial). Mas o PDF possui um foco mais estrutural, ligado à indústria de base, estando mais aberto a todas as empresas interessadas em participar, enquanto o Projeto Vínculos foca nas necessidades indicadas pelas grandes empresas e suas carências de fornecimento. Outro aspecto que os diferencia está na metodologia empregada. O PDF possui três vetores de atuação: capacitação de empresários, gestores, trabalhadores e empresas; promoção e divulgação das empresas e entidades de classe; assessoria empresarial para realização de negócios (DVF Consulto- 
ria, 2008). O Projeto Vínculos (na Bahia, onde o programa já está mais consolidado) se utiliza da certificação de um instituto terceirizado, o Instituto Baiano de Metrologia e Qualidade (Ibametro). Na avaliação inicial feita com empresas, são avaliados três grandes temas: os critérios básicos se referem a documentos sobre sanidade fiscal e econômica da empresa; os critérios classificatórios se referem à gestão empresarial, qualidade, meio ambiente, saúde e segurança no trabalho e responsabilidade social; o critério classificatório é a avaliação da empresa fornecedora.

Tanto no PDF quanto no Projeto Vínculos identificou-se que as empresas fornecedoras que participam do programa são, na maior parte, fornecedoras de serviços e, na maior parte dos programas analisados, há uma predominância de fornecedores de produtos/serviços relacionados ao ambiente interno e de rotina da grande empresa compradora. Não se pode inferir, portanto, em melhorias de produtos da cadeia de produção, mas na melhoria de empresas que estão em etapas de suporte da cadeia de suprimentos. Observa-se que o objetivo da área de compras é o de obter um produto especificado, com qualidade, incluindo o seu processo de produção, como evidenciado numa das entrevistas com uma empresa âncora compradora:

o fornecedor entrega o serviço no estado da arte, mas está sem pagar o FGTS dos empregados. E isto não nos interessa (...) imagine um trabalho do estado da arte e, por exemplo, metade dos trabalhadores com problema de saúde ocupacional. Então, essa é a finalidade da qualificação.

Para analisar a relação entre empresas, utilizou-se a estrutura teórica proposta por Gefferi e outros (2005), que classifica os padrões de relacionamento de compra e venda sob a perspectiva de três variáveis: complexidade das informações (informações necessárias para a execução da cadeia de valor, especialmente no que se refere às especificações de processos de produtos); habilidade de codificação: se as informações sobre uma transação específica podem ser codificadas e decodificadas, transmitidas, assim, com baixo custo (depende tanto da complexidade da informação quanto do esforço das empresas para codificálas); capacidade dos fornecedores (se os fornecedores estão aptos a atender as exigências das grandes empresas compradoras com relação às transações).

\section{Capacitação e padrões de transferência de tecnologia}

No que se refere aos relacionamentos entre as empresas e o padrão de transferência de tecnologia verificou-se baixa complexidade das informações, já que 
a maior parte das transações refere-se às operações de rotina e manutenção. Ainda que se exijam conhecimentos técnicos específicos e normas de segurança rígidas, infere-se, pelas entrevistas, um ambiente de baixa complexidade tecnológica de fabricação de bens e prestação de serviços no atendimento às empresas âncoras. A confiabilidade da informação dos programas analisados pode ser classificada tanto como alta, quanto baixa, pois determinadas empresas já possuem tal habilidade, enquanto outras se encontram em padrões menos desenvolvidos. A codificação, da mesma forma, para os produtos oferecidos nos programas enquadra-se como de baixa dificuldade. $O$ ponto positivo desse critério é que, nas empresas dos programas estudados, a codificação dos produtos e procedimentos para seus produtos de venda não envolve tecnologia de ponta, o que facilita e melhora nesse quesito. Quanto à capacidade do fornecedor, o que se tem é alta capacidade de desenvolvimento das atividades, mas com baixa capacidade administrativa/gerencial, justamente o principal ponto a desenvolver objetivado pelo Projeto Vínculos e pelos PDFs.

Como a complexidade de transações é uma classificação inerente ao tipo de produto, para as empresas que hoje atuam transações complexas ocorrerão apenas se novos tipos de transações forem desenvolvidos. Pela natureza dos produtos oferecidos, parceria em treinamento e gestão e certificações oferecidas, é factível se chegar a altos níveis de habilidade de codificação pelas empresas fornecedoras. Quanto à capacidade dos fornecedores, os resultados dos primeiros projetos já mostram que é possível aumentá-la, especialmente no caso de empresas que possuem ótimos serviços técnicos, mas falhas na capacidade de gestão.

Nos programas analisados, os padrões de transferência de tecnologias (Jeppesen e Hansen, 2004) foram prioritariamente de melhorias em práticas de gestão e adequação a quesitos mínimos de qualidade na gestão, sem, portanto, chegar ao nível de tecnologia de produção. Nos casos estudados, não houve exemplos da presença de técnicos das empresas âncoras nas empresas fornecedoras, mas organizações externas foram contratadas para treinamento in company dos fornecedores, como diagnosticado no trecho da entrevista da empresa âncora do PQF Bahia:

toda nossa parte de capacitação é terceirizada; trabalhamos com o Sesi, na área de saúde, segurança e responsabilidade social; com o Senai, na área de meio ambiente; qualidade e gestão empresarial é junto com o Sebrae. Assim que o fornecedor faz adesão ao programa, fazemos um diagnóstico e a empresa entra num processo de capacitação, sendo avaliada com relação a critérios com base nas necessidades da empresa âncora. 
Quanto aos benefícios dos programas de promoção de vínculos, as empresas fornecedoras identificaram a aquisição de práticas e técnicas de gestão, conhecimento sobre legislação vigente e posterior adequação, aumento de volume de negócios, facilidade ao acesso às entidades de classe, fortalecimento de laços de negócios com clientes geograficamente próximos e capacitações internas a baixo custo.

O conhecimento da lei vigente, por exemplo, nem sempre é de conhecimento das MPMEs. Certificados como o de licença ambiental, fundamentais para negociação com empresas exportadoras eram, em alguns casos, simplesmente desconhecidos ou ignorados. Os programas têm a vantagem de prover esse conhecimento para a adequação de tais empresas às exigências legais.

Os benefícios para as empresas âncoras dos VNs, citados nas entrevistas, foram: maior confiança no fornecedor, manutenção do fornecimento no longo prazo (evitando a troca constante do fornecedor), relacionamento que gera maior conhecimento, pelo fornecedor, das exigências e necessidades da empresa âncora. Tendo a garantia da continuidade do fornecedor, a empresa compradora se assegura de que seu fluxo de atividades não será interrompido por problemas de fornecimento.

Em uma das entrevistas foi afirmado que na região Nordeste, apesar de existir consumo significativo e incentivos fiscais para que a empresa âncora ali se estabeleça, há grande dificuldade de se encontrar fornecedores qualificados, valendo a pena a manutenção de fornecedores das regiões Sul e Sudeste, o que seria antagônico ao modelo ideal de desenvolvimento regional, principalmente considerando as desigualdades regionais brasileiras. Outro problema detectado foi que a relação informal entre executivos das empresas permitia identificar e disseminar a informação sobre as melhores e piores práticas dos fornecedores da região, levando aos melhores negócios os fornecedores mais bem capacitados e alijando os menos preparados do mercado. Essa rede informal não leva a um relacionamento comercial sustentável, identificando apenas os melhores e piores, conferindo solução somente para o curto prazo.

\section{A figura do Estado}

Em todas as entrevistas foram realizadas perguntas sobre o papel do Estado como promotor do desenvolvimento dos VNs. Até 2008, nas atividades do Projeto Vínculos, não havia qualquer parceria com órgãos governamentais. Nos PDFs, porém, houve ações mais coordenadas entre as instituições e o poder público, que foi desde o apoio institucional e financeiro, até a coordenação do 
governo estadual no caso do PDF-Maranhão. Pretendeu-se verificar as práticas que deram certo ou identificar oportunidades de associação entre a administração pública e os programas, as possíveis formas de incentivo e em quais situações a interferência do Estado é indesejável.

O primeiro desafio a ser superado é a imagem ruim que o Estado possui quanto à sua capacidade de se envolver em assuntos típicos da iniciativa privada. Por exemplo: quando uma empresa fornecedora foi questionada sobre a atuação do governo no programa desenvolvido, obteve-se a seguinte resposta: “(...) para mim, a única obrigação do governo é reduzir meu imposto, porque ele não tem capacidade, competência, não tem gerência...”. Em relação às instituições públicas de fomento, como os bancos, tem-se a percepção de que existe muita dificuldade para a obtenção dos recursos: "minha percepção é que a burocracia é muito grande, tem toda uma dificuldade, mas que dentro do programa está previsto uma rodada de negociação com esses bancos...". Outro aspecto negativo percebido do Estado é a possibilidade de uso político do programa e consequente mudança de foco:

um dos pilares básicos desse programa foi ser apolítico, porque ele não é plataforma de campanha de ninguém (...) caso contrário, algo que era para benefício das empresas termina beneficiando poucas pessoas. E queremos que as empresas se perpetuem no mercado, cresçam e gerem emprego e, consequentemente, imposto para o Estado.

Entretanto, bons exemplos foram citados com a aproximação da administração pública:

fazemos programas com a prefeitura, porque nossa empresa está instalada no parque industrial da cidade, e temos um programa de usar mão de obra local, de trazer empresas fornecedoras para cá (...) e, de certa forma, recebemos incentivo fiscal. Existe também um treinamento interno, custeado pela empresa, com parceria de universidades e instituições federais, estaduais e municipais.

Outro exemplo positivo do Estado veio da entrevista com o PDF-Maranhão. Com a privatização da empresa âncora, ocorreu um choque no ambiente de negócios e muitas empresas fornecedoras não estavam preparadas para a nova realidade. Isso abriu oportunidade para que empresas de outros estados, principalmente das regiões Sul e Sudeste, mais competitivas, ali se instalassem. E foi a partir dessa constatação que se viu a necessidade de se criar um programa que qualificasse os fornecedores. O Estado foi, então, o indutor de um processo 
que unia o interesse das empresas, fornecedoras e compradoras, entidades de classe (criadas para dar apoio e sustentação às empresas) e Estado: "Fizemos o lançamento do programa, identificamos as demandas dessas grandes empresas e percebemos que tínhamos que atuar primordialmente na questão da gestão, por meio de parcerias com a Secretaria do Trabalho, Senai, Senac etc.".

Na criação do PDF-Espírito Santo, mais do que apoio financeiro, foi importante o apoio institucional. Hoje, sua administração se dá pela Secretaria de Estado da Indústria e Comércio, com decisões importantes delegadas a um comitê gestor, no qual o governo participa junto com as empresas parceiras do programa.

\section{Identificação de spillovers}

Observaram-se spillovers entendidos como benefícios diretos e indiretos dos VNs para a economia local nos programas pesquisados, ainda que a literatura (Girma et al., 2008) seja controversa em relação a como identificá-los e sua relação direta com os VNs. Por exemplo: foram observados resultados positivos na promoção de fóruns de fornecedores, ambiente em que eles se encontram periodicamente para discutir problemas comuns, fazendo com que se interajam e busquem competitividade, como observado na entrevista a um pequeno fornecedor local: "(...) essa empresa está vendendo bastante para a empresa âncora porque ele atua assim, então eu quero me capacitar para chegar ao nível dele".

Ainda que existam benefícios para a empresa fornecedora e que a qualificação seja feita para melhoria de desempenho no mercado, sua adesão aos programas nem sempre ocorre de maneira fácil e automática. Existem fatores culturais e de maturidade da empresa que influenciam tal adesão. No Projeto Vínculos, o convite para que as empresas se engajem no programa é chamado de "sensibilização de empresas". O entrevistado do programa afirma que a maneira encontrada para atrair o maior número de empresas é, primeiramente, sensibilizar a âncora e, depois, as fornecedoras, preferencialmente no ambiente da âncora:

as lições aprendidas dos projetos indicam que a reunião de sensibilização seja feita na própria empresa âncora, com o seu próprio convite, pois ficam claras as oportunidades para as fornecedoras se qualificarem para atender necessidades específicas das âncoras que gerem negócios. É muito diferente sensibilizar a MPME no ambiente da grande empresa, em vez de sensibilizá-la na Federação das Indústrias ou no Sebrae, por exemplo. 
Um desafio na fase de sensibilização é a percepção de que informações serão compartilhadas das mais diversas formas. Da perspectiva do fornecedor, pode haver o receio de se perder autonomia do negócio, além da exposição das principais deficiências internas para parceiros econômicos importantes. Como no início do vínculo é realizada uma avaliação da situação inicial das empresas fornecedoras, as deficiências podem significar barreiras iniciais impostas pelas empresas âncoras compradoras. Isto pode ser um argumento que enfraquece a ação do Estado como condutor direto desses tipos de programas de VN, pois os resultados de uma avaliação desses fornecedores podem servir de material para ações punitivas, como multas. Assim, um dos principais fatores do sucesso inicial desses programas é a confiança, tanto no programa como um todo quanto nas organizações participantes.

\section{Considerações finais}

A força dos programas analisados está na sinergia entre empresas (âncoras compradoras e pequenas fornecedoras), poder público (como as secretarias estaduais de desenvolvimento), organizações do terceiro setor (como organizações não governamentais), entidades de classe (como federações de indústria), serviços de desenvolvimento de negócios (como o Sebrae) e agências de promoção de investimentos (como Indi e Polo-RS).

As empresas que ainda não possuíam qualquer tipo de parceria com o Estado, geralmente tinham uma imagem negativa da ação do poder público, preferindo, inicialmente, manterem-se afastadas dos programas de desenvolvimento de VN que apresentavam participação clara de órgãos públicos. Mas essa perspectiva geralmente muda quando experimentam a parceria, como no caso de algumas empresas âncora entrevistadas. Em alguns casos, a atuação do Estado ocorre por meio de incentivo financeiro (doação de terrenos, incentivos fiscais etc.), forma frequentemente criticada na literatura (Almeida et al., 2007; Giroud e Botelho, 2008), já que parece não ser justo o Estado, principalmente em países em desenvolvimento, incentivar financeiramente MNCs, muitas delas com faturamento superior ao valor de produtos internos brutos de certos países. Entretanto, foi observado que os incentivos financeiros do governo local tinham como contrapartida o investimento em treinamento e capacitação de mão de obra local, objetivos que também estão previstos nos programas de VN, mostrando que esse tipo de incentivo financeiro, com caráter de longo prazo, pode ser viável. 
Não foram identificadas políticas federais específicas para a formação de VN, apenas em nível estadual, especialmente no caso dos PDFs. Os programas desenvolvidos com parceria de governos locais mostraram-se bem articulados, indicando que o Estado pode não ser um agente fundamental para os programas de geração de $\mathrm{VN}$, mas sua participação pode trazer benefícios mais abrangentes, com alcances mais profundos e estruturais nas comunidades locais ou na própria sociedade. Então, o Estado pode sim desenvolver políticas públicas para estimular o desenvolvimento de VN, mas sob as condições a seguir, identificadas na pesquisa empírica.

- Complemento às políticas de desenvolvimento: política complementar de criação de vínculos para o fortalecimento da política industrial local ou regional. O estado do Maranhão, por exemplo, buscava fortalecer seu perfil industrial e, para isso, usou mais do que incentivos fiscais para que empresas ali se instalassem. Para complementar a política industrial, foi realizado um programa de fortalecimento de $\mathrm{VN}$, pois sem empresas fornecedoras de qualidade, os custos de produção aumentariam e as condições para permanência de empresas âncoras seriam bem menos atrativas.

- Atuação como política de educação e qualificação de profissionais: quando um programa de promoção de VN é desenvolvido, é possível identificar problemas comuns nas empresas e formar grupos específicos para cada um deles, além de promover a troca de experiência e aprendizagem entre os profissionais das diversas empresas participantes, fazendo com que existam ganhos de escala em treinamento e qualificação.

- Complemento a políticas de atração investimentos: ao tentar atrair uma empresa para se instalar no Estado, o governo deve garantir que ela tenha condições mínimas de atuação, como uma indústria de base e fornecedores de serviços básicos. Caso esse ambiente não exista, em vez de políticas de abordagem restritiva (como criar critérios que obriguem as grandes empresas a comprar de fornecedores locais), há alternativas de incentivo para que as empresas voluntariamente participem de programas de geração de vínculos, como o incentivo de qualificação da mão de obra e desenvolvimento gerencial de fornecedores.

- Incentivo à transferência de tecnologia: nos casos estudados não houve ocorrência explícita de transferência de tecnologia. As grandes empresas, especialmente multinacionais, podem ser importantes atores nesta transferência e o Estado possui capacidade para atrair MNCs em sua política de atração de investimentos. Pode haver tal transferência de tecnologia quando, por 
exemplo, houver terceirização para as MPMEs locais de etapas de produção das MNCs. Também pode ser estimulada a participação de instituições de pesquisa e universidades, potencializando o desenvolvimento de tecnologia e sua transferência para as empresas locais.

- Desenvolvimento do ambiente de negócios: foi detectado na pesquisa empírica que o simples fato de colocar empresas em contato umas com as outras faz com que novos negócios se realizem. Ainda que os programas tivessem como objetivo principal os vínculos do tipo comprador-fornecedor, verificou-se o aumento do volume de negócios do tipo fornecedor-fornecedor. Isso porque as MPMEs fornecedoras estão em diferentes etapas da produção e umas podem ser fornecedoras de outras e estas últimas, fornecedoras da âncora. Portanto, o Estado pode estimular a dinâmica local, promovendo fóruns entre empresas a fim de discutir problemas e soluções que atuem em conjunto.

O conflito de interesses pode afastar governos da gestão de programas de VN, pois abrir uma empresa a entidades governamentais gera desconfiança da iniciativa privada, principalmente para as empresas com alguma irregularidade, o que pode não ser raro em MPMEs. Nesse aspecto, a instituição terceira é mais bem-vista para intermediar os interesses das empresas com as contrapartidas governamentais. Organizações do terceiro setor e serviços de desenvolvimento de negócios (como o Sebrae) podem ter maior legitimidade para gerenciar e articular um programa de VN. Outro aspecto é que, por mais que empresas possuam know-how tecnológico e capacidade administrativa, capacitação tecnológica e gerencial, geralmente estão além de seu core business. Essas ações podem ser mais eficientes quando desenvolvidas e articuladas por organizações especializadas em capacitação, como é o caso do Sebrae.

Políticas de VN podem ser importantes complementos para as políticas industriais e de desenvolvimento locais. Para os estados que possuem empresas mais qualificadas deve-se considerar a geração de vínculos com o foco na transferência de tecnologia, também em complemento à política industrial.

Este artigo possui limitações que podem ser consideradas em futuras pesquisas. O caráter exploratório aqui utilizado pode ser complementado com futuras pesquisas de natureza quantitativa, podendo-se, inclusive, medir resultados dos programas e spillovers.

Programas de estímulo aos VNs criados e gerenciados exclusivamente pelas grandes empresas (como o Programa de Garantia de Qualidade de Materiais e Serviços Associados da Petrobras e o Programa de Desenvolvimento da Cadeia e Valor Basf) não foram considerados neste artigo. Portanto, a efetivi- 
dade de tais programas, ocorrência de spillovers e impacto na cadeia de valor podem ser considerados em futuras pesquisas. Poderiam ser analisados, por exemplo, os objetivos de uma empresa arcar unilateralmente com um programa dessa natureza, se baseado na lógica econômica apenas, na racionalidade de responsabilidade social ou em ambas. Ainda que dois tipos de programas (PDFs e Projeto Vínculos) tenham sido abordados, não foi considerada a modelagem organizacional, que pode ser uma forma de compreensão mais aprofundada de seu funcionamento, além de permitir mais insights sobre a melhor maneira de atuação do Estado.

Foram aqui avaliadas condições para que as políticas públicas sejam desenvolvidas, mas não as formas. Analisar e propor desenho de políticas públicas, sob aspectos legais e seus impactos gerenciais, são estudos de grande valor na área de VN. De modo complementar, também poder-se-ia analisar sistemas de governança, tanto os que abrangem a relação entre as empresas quanto os que tratam da conexão com o setor público.

\section{Referências}

ALMEIDA, A.; CRETOIU, G.; MENDONÇA, G. D.; ROSSETTI, J. P.; RESENDE, P. T. $\mathrm{V}$. The Brazilian case on international good practices on TMC-SME linkages. Projeto Vínculos. Relatório de Pesquisa, 2007.

BOTELHO, D.; PFISTER, M. Policies and institutions on TNC-SME linkages: the Brazilian case. In: GLOBAL BUSINESS INNOVATION AND DEVELOPMENT CONFERENCE VII. Proceedings... Rio de Janeiro, 2008.

BRESSER-PEREIRA, L. C. Gestão do setor público: estratégia e estrutura para um novo Estado. In: BRESSER-PEREIRA, L. C.; SPINK, P. Reforma do Estado e administração pública gerencial. Rio de Janeiro: FGV, 2003.

COVIELLO, N. E.; BRODIE, R. J. From transaction to relationship marketing: an investigation of managerial perceptions and practices. Journal of Strategic Marketing, n. 6, p. 171-186, 1998.

DVF Consultoria. Programa de Desenvolvimento de Fornecedores. O que é PDF. Disponível em: <www.dvf.com.br/pdf.aspx>. Acesso em: 15 jun. 2008.

GEFFERI, G.; HUMPHREY, J.; STURGEON, T. The governance of global value chains. Review of International Political Economy, v. 12, n. 1, p. 214-228, 2005.

GIRMA, S.; GÖRG, H.; PISU, M. Exporting, linkages and productivity spillovers from foreign direct investment. Canadian Journal of Economics, v. 41, n. 1, p. 320340, 2008. 
GIROUD, A. Is government support really worth it? Developing backward linkages in Malaysia. In: TAVARES, A.; AURORA, A. C. T. (Eds.). Multinationals, clusters and innovation: does public policy matter? Basingstoke: Palgrave MacMillan, 2006.

. MNEs vertical linkages: the experience of Vietnam after Malaysia. International Businesse Review, v. 16, p. 159-176, 2007.

; BOTELHO, D. Policies promoting MNEs linkages in host economies: a comparison between Brazil and Malaysia. In: GLOBAL FORUM OF INVESTMENT, OECD. Proceedings... Paris, 27-28 Mar. 2008.

GONÇALVES, J. E. P. Empresas estrangeiras e transbordamentos de produtividade na indústria brasileira: 1997-2000. Dissertação (Mestrado) — Universidade Estadual de Campinas, 2005.

IVARSSON, I.; ALVSTAM, C. G. International technology transfer through local business linkages: the case of Volvo Trucks and their domestic suppliers in India. Oxford Development Studies, v. 32, n. 2, p. 241-260, 2004.

JENKINS, B.; AKHALKATSI, A.; ROBERTS, B.; GARDINER, A. Business linkages: lessons, opportunities and challenges. In: IFC, INTERNATIONAL BUSINESS LEADERS FORUM, AND THE KENNEDY SCHOOL OF GOVERNMENT. Proceedings... Cambridge: Harvard University, 2007.

JEPPESEN, S.; HANSEN, M. W. Environmental upgrading of Third World enterprises through linkages to transnational corporations: theoretical perspectives and preliminary evidence. Business Strategy and Environment, v. 13, n. 4, p. 261-275, 2004.

KETTL, D. F. A revolução global: reforma da administração do setor público. In: BRESSER-PEREIRA, L. C.; SPINK, P. Reforma do Estado e administração pública gerencial. Rio de Janeiro: FGV, 2003.

KRAUSE, D. R.; HANDFIELD, R. B.; SCANELL, T. V. An empirical investigation of supplier development: reactive and strategic process. Journal of Operations Management, n. 17, p. 39-58, 1998.

; HANDFIELD, R. B.; TYLER, B. B. The relationships between supplier development, commitment, social capital accumulation and performance improvement. Journal of Operations Management, n. 25, p. 528-545, 2007.

KUMAR, S.; BERGSTROM, T. An exploratory study of the relations between the U.S. manufacturers and their local distributors in developing markets. Information Knowledge Systems Management, v. 7, n. 3, p. 301-334, 2008.

LANGFIELD-SMITH, K.; GREENWOOD, M. R. Developing co-operative buyer-supplier relationships: a case study of Toyota. Journal of Management Studies, v. 35, n. 3, p. 331-353, 1998.

MINISTÉRIO DO DESENVOLVIMENTO, INDÚSTRIA E COMÉRCIO EXTERIOR. Mais desenvolvimento e exportações com política industrial. Disponível em: <www2. 
desenvolvimento.gov.br/sitio/ascom/noticias/noticia.php?cd_noticia $=5482>$. Acesso em: 23 nov. 2009.

MEYER-STAMER, J. Good practices in the promotion of businesses linkages from an operational perspective: evidence from the field. Mesopartner, Dec. 2005.

MOREIRA, J. C. T. Marketing industrial. 2. ed. São Paulo: Atlas, 2002.

OBSERVATÓRIO SOCIAL. Os investimentos das multinacionais no Brasil, panorama histórico, tendências recentes e o desafio do desenvolvimento com promoção de direitos. São Paulo: Observatório Social, 2005.

PNEUVITA CERTIFICADO MICHELIN. Disponível em: < www.pneuvita.pt/public/ Text.php?text_id=24>. Acesso em: 20 set. 2008.

PROJETO VÍNCULOS METODOLOGIA. Disponível em: <www.projetovinculos. org >. Acesso em: 14 mar. 2009.

SAKO, M. Supplier development at Honda, Nissan and Toyota: comparative case studies of organizational capability enhancement. Industrial and Corporate Change, v. 13, n. 2, p. 281-308, 2004.

SARAVIA, E. Introdução à teoria da administração pública. In: SARAVIA, E.; FERRAZERI, E. Políticas públicas. Brasília: Enap, 2006. Coletânea.

SERVIÇO BRASILEIRO DE APOIO ÀS MICRO E PEQUENAS EMPRESAS. Fatores condicionantes e taxas de sobrevivência e mortalidade das micro e pequenas empresas no Brasil 2003-2005. Brasília: Sebrae, 2007.

Sebrae, 2008.

Anuário do trabalho na micro e pequena empresa 2008. 2. ed. Brasília:

SHEN, X. Linking local suppliers to multinationals: how can governments play a useful role? Beyond Transition. The World Bank Group. Disponível em: <www. worldbank.org >. Acesso em: 20 jan. 2008.

SILVA, J. E. Um modelo de programa de desenvolvimento de fornecedores em redes de empresas. Tese (Doutorado) - Programa de Pós-Graduação em Engenharia de Produção, Universidade Federal de Santa Catarina, 2004.

UNITED NATIONS CONFERENCE ON TRADE AND DEVELOPMENT. Report on the expert meeting on business linkages. Geneva, 2006.

. World investment report 2008. Geneva: Unctad, 2008.

WEBSTER JR., F. E. Industrial marketing strategy. 3. ed. New York: John Wiley \& Sons, 1991.

YIN, R. K. Case study research: design and methods. 3. ed. Los Angeles: Sage Publications, 2005. 